\title{
La manipulación de la causa alfonsina en Castilla, 1464-1468
}

\author{
Paz Romero Portilla *
}

\begin{abstract}
RESUMEN
En los dificiles años que tuvieron lugar entre la proclamación como "rey" del infante Alfonso y su muerte, apenas tres años después, Castilla vivió unos momentos de división y enfrentamiento. La institución monárquica en la persona de Enrique IV fue atacada, debilitada en sus funciones e insultada, por un grupo de nobles que buscando, en su mayor parte, conseguir beneficios y poder, alzaron a un niño como "rey». Durante estos años fue la nobleza la que gobernó el reino utilizando la figura del rey, en un caso por indefensión y en otro por debilidad. En ambos casos, tanto Alfonso como Enrique IV fueron

títeres de un poder oligárquico que trataba de hacerse con el gobierno de Castilla. Sin duda el partido portugués, formado por miembros de familias de ascendencia lusitana fueron protagonistas en estos tristes sucesos.
\end{abstract}

PALABRAS CLAVE: Edad media. Siglo XV. Castilla. Nobleza. Exiliados portugueses.

\section{ABSTRACT}

During the hard years that passed between the proclamation of the infant Alphonse as a "king" and his death, only three years later, the kingdom of Castile suffered the effects of partition and confrontation. The monarchical institution in the person of Henry IV, was attacked, weakened in its functions and insulted by a group of noblemen who searching for power established a boy like a "king". The nobility governed the kingdom on behalf of the king, on one hand because of defenselessness and on the other because of weakness. In both cases, Alphonse as well as Henry were puppets of an oligarchical power that tried to get the government of Castile. Undoubtedly, the Portuguese party made up of families of a Portuguese origin, were protagonists in these sad events.

\section{KEYWORDS:}

Middle Age. $15^{\text {h }}$ Century. Castile. Nobility. Portuguese exiles.

* Universidade da Coruña 
Entre 1464 en que Juan Pacheco consiguió que se le entregase la custodia del infante Alfonso hasta la muerte de éste en 1468, un grupo de nobles dirigidos por el marqués de Villena provocaron gran división e inestabilidad en Castilla, debilitando aún más la institución monárquica y consiguiendo así sus principales objetivos; enriquecimiento y poder. Este grupo de nobles de ascendencia portuguesa estaba en su mayoría emparentado con Juan Pacheco: Nos referimos a su hermano el maestre de Calatrava, Pedro Girón; a su tío el arzobispo de Toledo, Alfonso Carrillo; y a su yerno el conde de Benavente, Rodrigo Alfonso Pimentel.

Desde su exilio a Castilla a finales del S. XIV algunos portugueses comenzaron su ascenso social y económico. En una o dos generaciones miembros de estas familias tendrán ya, gracias a las donaciones de bienes y títulos recibidos, un poder político destacado. Ocuparán puestos decisivos en la corte durante el reinado de Enrique IV y en muchas ocasiones se hicieron con el poder efectivo del reino. En los años que ahora nos ocupan, este grupo se enfrentó al monarca apoyando a su hermano Alfonso, al que llegaron a titular rey de Castilla. Sin duda, son unos años tristes para la institución monárquica, donde el poder nobiliario se enfrentó nuevamente al poder real ${ }^{1}$. En esta ocasión el poder oligárquico estaba defendido por el partido portugués, formado principalmente por miembros de las familias Pacheco, Pimentel, Acuña y Portocarrero.

Desde 1461 las maniobras políticas en Castilla del marqués de Villena estuvieron encaminadas a debilitar el poder real. Juan Pacheco y el arzobispo de Toledo tenían fuerza gracias al respaldo de la liga nobiliaria. Solamente el linaje de los Mendoza podía enfrentarse a este poder alcanzado por los Pacheco, Girón y el arzobispo Carrillo, en defensa de la autoridad real.

A Juan Pacheco, protagonista indiscutido de los acontecimientos ocurridos en este momento, no parecen importarle ni el rey Enrique IV ni su hermano Alfonso; su actuación se redujo a boicotear las decisiones y acuerdos que significaban la formación de un poder más fuerte al suyo, incluyendo el de la institución monárquica. Su único interés fue el poder personal, consecuencia de su ascenso económico y social así como el de su familia $^{2}$. Por tanto es difícil encuadrarlo en algún partido nobiliario que no

Sobre este aspecto un buen referente es la obra de SuÁRez Fernandez, Luis: Nobleza y Monarquía. Puntos de vista sobre la historia política del siglo xv, (Valladolid), 1959. (= SUÁREZ FERnÁndez, Nobleza y Monarquía)

2 Consiguió formar un linaje tan fuerte y rico que su presencia política en el reino fue indiscutible. Ver el artículo ROMERo PORTILLA, P. "Protagonismo político del partido portugués en la política castellana del s. Xv". (En imprenta) 
sea el formado por él y su familia más cercana, de hecho son constantes sus cambios de postura y de bando dependiendo del beneficio propio. Siguiendo con su política de aprovecharse de las situaciones, Juan Pacheco continuó jugando con los dos bandos. En marzo de 1462 el marqués de Villena estuvo presente en el nacimiento de la hija de Enrique IV, donde su mujer fue, junto con Isabel la hermana del rey, madrina de Juana, y Juan Pacheco, junto con el embajador de Francia, el conde de Armañac, fue el padrino. Posteriormente los grandes del reino juraron a la princesa Juana como heredera ${ }^{3}$. Ese mismo año en el monasterio de Cisla, junto a Toledo donde se encontraba Enrique IV, tuvo lugar la junta convocada por el marqués de Villena a la que acudieron el arzobispo de Toledo, el maestre de Calatrava y otros amigos, y donde se trató de antiguas quejas de los nobles y del comportamiento del rey castellano ${ }^{4}$. Todavía en marzo de 1463 Enrique IV envió a Juan Pacheco y al arzobispo de Toledo a Bayona a preparar una entrevista con el rey de Francia ${ }^{5}$. El encuentro tuvo lugar en mayo y el rey castellano fue acompañado por el marqués de Villena.

Un año después comenzó la crisis política al renacer con nueva fuerza la liga nobiliaria. La crónica indica como el desplazamiento de Juan Pacheco de la corte fue el comienzo de la misma ${ }^{6}$. El marqués de Villena quiso utilizar la liga como medio para recobrar el poder y supo aglutinar en ella a los nobles descontentos, convirtiéndose en la figura clave del momento. En mayo de 1464, los parientes Alfonso Carrillo de Acuña, Juan Pacheco y Pedro Girón organizaban la nueva liga para desestabilizar el poder real y hacerse con la custodia de los infantes ${ }^{7}$. Fueron muchos los nobles que se adhirieron a la liga, incluido el infante

3 1462.05.16. Madrid. Carta de Enrique IV a Rodrigo Pimentel mandándole jurar a la princesa como lo habian hecho los grandes del reino. Memorias de Enrique IV, n. ${ }^{\circ}$ LXXIV, pp. 247-248.

4 Palencia, Alfonso de, Crónica de Enrique IV, BAE, Madrid, 1973, tomo I, libro VI, cap. VI. (= Palencia, Crónica de Enrique IV

5 1462.03. PALENCIA, Crónica de Enrique IV, libro VI, cap. VII.

6 «Indignábanle al Marqués tales hechos, no precisamente por lo que tenian de contrarios a la dignidad, sino por los recelos que le inspiraban de perder su consideración o su vida, y cuando vio que en el gobierno se procedia cada vez más extraña y desatentadamente, y que en su ausencia y sin su consejo se reunian a tratar los Reyes se conjuró con aquellos Grandes que de largo tiempo venían oponiéndose al escándalo y a la corrupción, porque sabía de cierto que volvería a ganarse sus voluntades cuantas veces les asegurase, con verdad o con engaño, que tomaba la defensa de la corrección de las costumbres o de la observancia de las leyes". Ibídem, libro VII, cap. I.

1464.05.16. Confederación entre Alfonso Carrillo. Pedro Girón y Juan Pacheco para procurar la seguridad de los infantes Alfonso e Isabel. Memorias de Enrique IV, n. XCIl, pp. 302-304 A.H.N. Sección Nobleza. Frias, caja 696, doc. 11. 
Juan, ahora rey de Aragón ${ }^{8}$. En el enfrentamiento con el monarca, el marqués de Villena y su hermano llegaron a levantar las armas frente al monarca. En septiembre de 1464 Juan Pacheco convocó una junta de nobles en Burgos, en la que se encuentran entre otros, los Carrillo, Girón, Pimentel y Acuña ${ }^{9}$. La decisión de la junta fue enviada a las ciudades del reino y en ella se acusó gravemente a Enrique IV por proteger a los musulmanes poniendo en peligro la fe cristiana, entregar el poder a Beltrán de la Cueva, quebrantar la moneda y proyectar la muerte de los infantes. A pesar de que los seguidores de Enrique IV se inclinaban por una acción militar enérgica el rey castellano decidió negociar con los nobles ${ }^{10}$, este hecho supuso según afirma Suárez Fernández el primer paso hacia la capitulación total de la monarquía ${ }^{11}$. La negociación fue dirigida por el marqués de Villena que conocía la debilidad de Enrique IV, en ella trató de alejar del favor real a Beltrán de la Cueva, debilitar el poder de la familia Mendoza, que la custodia del infante Alfonso pasase a los nobles, convertir al rey castellano en un instrumento en manos de la liga nobiliaria y reformar el consejo para que el poder lo tuvieran los grandes ${ }^{12}$. Realmente la negociación fue enormemente beneficiosa para Juan Pacheco, ya que consiguió que se le entregase en custodia al infante Alfonso ya nombrado heredero ${ }^{13}$, convertirse en su tutor ${ }^{14}$, la ad-

8 Son numerosos los documentos que recogen las confederaciones de Juan Pacheco con diversos miembros de la nobleza castellana para asegurarse su colaboración y apoyo. 1464.05.23. Confederación entre Alfonso Carrillo, el almirante Fadrique, el conde de Alba de Liste, el conde de Paredes Rodrigo Manrique y su hermano Enrique, prometiendo a Juan Pacheco y su hermano Pedro Girón leal amistad, siendo unos para unos y todos para todos, para la conservación de sus vidas y haciendas. Acompaña un documento de seguridad dado por el arzobispo de Toledo en el que promete que el rey de Aragón cederá al marqués de Villena y al maestre de Calatrava los lugares que tenía en Castilla. A.H.N. Sección Nobleza. Frías, caja 12, doc. 2; 1464.08.06. Pleito homenaje y confederación con Juan Pacheco del conde de Plasencia, Álvaro de Estúñiga. Ibídem. caja 13, doc. 13; 1464.08.07. Confederación de García de Toledo, conde de Alba, con Juan Pacheco. Ibídem, caja 13, doc. 14; 1464.11. Confederación de Rui Díaz de Mendoza y Álvaro de Mendoza con Juan Pacheco. Ibídem, caja 13, doc. 15.

9 Palencia, Crónica de Enrique IV, libro VII, cap. III.

10 Las vistas tuvieron lugar en Cabezón cerca de Cigales. 1464.11.30. Asiento entre Enrique IV y los nobles sobre diversos asuntos del reino, hicieron juramento y pleito-homenaje de cumplir lo acordado en manos del marqués de Villena. A.H.N. Sección Nobleza. Frías, caja 15, doc. 3, 4, 5.

11 SuÁrez, Nobleza y Monarquía, p. 208.

12 Ibídem, p. 209.

13 1464.10.25. Valladolid. Concierto celebrado por el rey con Juan Pacheco y entre éste y varios nobles del reino sobre la tutoría del infante Alfonso. Memorias de Enrique $\mathrm{N}, \mathrm{n} .{ }^{\circ} \mathrm{Cl}, \mathrm{pp} .337$ 340; 1464.11.30. Entre Cabezón y Cigales. Juramento de los nobles y grandes del reino, haciendo pleito-homenaje en manos del marqués de Villena, de aceptar como principe heredero al infante Alfonso. A.H.N. Sección Nobleza. Frías, caja 15, doc. 4-5.

14 De hecho, no tardó en actuar como tutor del infante Alfonso: 1464.12.06. Poder que dio Juan Pacheco a Lope de Acuña para que tomase en su nombre, como tutor del infante Alfonso. 
ministración del maestrazgo de Santiago ${ }^{15}$ y la participación en el consejo real ${ }^{16}$. Posteriormente los nobles rebeldes juraron a Alfonso como príncipe heredero y buscaron que fuera reconocido en todo el reino ${ }^{17}$.

A comienzos de 1465 Alfonso Carrillo pareció apoyar al rey castellano pero sin embargo se trataba de una hábil maniobra ya que secretamente continuaba con el marqués de Villena ${ }^{18}$. Siguiendo con su ambigua actitud Juan Pacheco comenzó nuevas negociaciones con el arzobispo de Toledo para reconstruir la liga de nobles. En ella se comenzó a hablar de deponer a Enrique IV pero el marqués de Villena no quería llegar a tal extremo, ya que buscaba mantenerse en un término medio que le fuera más beneficioso ${ }^{19}$. Finalmente la liga decidió destituir al rey castellano y proclamar rey a su hermano Alfonso ${ }^{20}$. En mayo de 1465 fue hecha la representación a Enrique IV por el conde de Plasencia, el marqués de Villena, el maestre de Alcántara y el conde de Benavente por ellos mismos y en nombre de los demás grandes del reino, quejándose de no haberse cumplido con lo dispuesto anteriormente y que se despedirian de su servicio si hacía la guerra al príncipe Alfonso ${ }^{21}$. Enrique IV pidió que se le entregase a su

Ibídem, caja 16, doc. 13; 1464.12.22. Poder de Juan Pacheco a Juan de Avellaneda para que tomase posesión de Portillo, en su nombre como tutor del infante Alfonso. Ibídem, caja 16, doc. 14.

15 1464.11.30. Cabezón. 33 cédulas de Enrique IV a los comendadores de Santiago, comunicándoles haber dado el maestrazgo al príncipe Alfonso. A.H.N. Sección Nobleza. Frías, caja 664, doc. 23-54; 1464.12.04. Enrique IV asegura al príncipe Alfonso y a Juan Pacheco su tutor, que no favorecía a Beltrán de la Cueva sobre la administración del maestrazgo de Santiago. Ibídem, caja 664, doc. 15; 1464.12.05. Cabezón. Enrique IV comunica que Beltrán de la Cueva, conde de Ledesma, ha renunciado al maestrazgo de Santiago y dispone que se entregue al príncipe Altonso. Ibídem, caja 664, doc. 16-17.

16 1464.11.30. Capitulación otorgada entre el rey y los Grandes para la pacificación del reino. Memorias de Enrique IV, n. ${ }^{\circ}$ Cll, pp. 340-345. A.H.N. Sección Nobleza. Frías, caja 15, doc. 3

17 Es abundante la documentación sobre este aspecto, una muestra son los siguientes documentos: 1464.12. a 1465.01. Certificados haciendo constar que las ciudades de Guadalajara, Molina, Madrigal, Logroño, Alfaro, Agreda y Villamayor, habian acatado la cédula de Enrique IV nombrando heredero a su hermano Alfonso. Ibidem, caja 16, doc. 1-12; 1464.12 a 1465.02 . Requerimientos a diversas villas y lugares para que se tuviera como príncipe heredero al infante Alfonso. Ibidem, caja 15, doc. 7-37; 1464.12 a 1465.04. Requerimientos al arzobispo de Santiago, conde de Medinaceli, marqués de Santillana, condestable de Castilla, y a las villas de Moya y Requena, para que jurasen como príncipe heredero al infante Alfonso. Ibidem, caja 15, doc. 38-43; 1464.12 a 1465.04 . Poderes de diferentes poblaciones para jurar como príncipe heredero al infante Alfonso. Ibídem, caja 15, doc. 44-70.

18 Palencia, Crónica de Enrique IV, libro VII, cap. IV-V.

19 Ibidem, libro VII, cap. V.

20 A comienzos de 1465 tuvo lugar la deliberación de los grandes del reino que seguian al príncipe Alfonso, por si convenía alzarle en el trono y deponer a Enrique IV. Memorias de Enrique IV, n." CXVIII, pp. 489-490.

${ }^{21}$ 1465.05.10. Plasencia. Ibídem, n. ${ }^{\circ} \mathrm{CXC}$, pp. 485-488. Del mismo dia es la confiscación hecha por el príncipe Altonso de los bienes de Juan de Ulloa por seguir a Enrique IV, hizo donación de los mismos al conde de Benavente. Ibidem, $n .{ }^{\circ} \mathrm{CXVI}$, pp. 488-489. 
hermano y ordenó a los nobles rebeldes deponer las armas y volver a su servicio. En junio los rebeldes abandonaron las negociaciones con al rey y tuvieron lugar los acontecimientos de Ávila, donde se trató de la deposición de Enrique IV y su legalidad jurídica ${ }^{22}$. Los nobles allí reunidos comenzaron un juicio contra el monarca representado en un muñeco vestido de rey: Alfonso Carrillo de Acuña, Diego López de Estúñiga y Rodrigo Alfonso Pimentel le fueron quitando, entre golpes y ofensas, los distintivos reales. Cuando la institución monárquica en Castilla tocaba fondo, los miembros de los linajes portugueses exiliados fueron protagonistas activos de tan desdichado suceso político. Pertenecieron al bando que apoyó la oligarquía nobiliaria frente a la autoridad real. En el alzamiento del príncipe Alfonso como «rey» y en su decidido apoyo frente a Enrique IV la presencia de varios miembros de estas familias portuguesas fue decisiva, basta mirar además de su actuación en la «farsa» de Ávila, la composición de la "corte" de Alfonso ${ }^{23}$. En el consejo real encontramos de canciller mayor al arzobispo de Toledo, Alfonso Carrillo de Acuña; como canciller mayor del Sello de la Poridad al conde de Benavente, Rodrigo Pimentel; como justicia mayor al conde de Plasencia, Álvaro de Estúñiga ${ }^{24}$; entre sus consejeros aparecen, el conde de Buendia, Pedro de Acuña, el arzobispo de Toledo, Alfonso Carrillo de Acuña, el maestre de Calatrava, Pedro Girón, el marqués de Villena, Juan Pacheco, el conde de Benavente, Rodrigo Pimentel, el señor de Palma del Río, Luis Portocarrero y el adelantado de Cazorla, Lope Vázquez de Acuña. En la casa del rey encontramos de mayordomo al marqués de Villena; de camarero mayor de armas a Lope Vázquez de Acuña; de guarda mayor al arzobispo de Toledo, Alfonso Carrillo y a Lope Vázquez de Acuña; como uno de los ofjciales de cuchillo a Lope de Acuña; y como camarero de la cámara de contaduría al maestre de Calatrava.

También resulta significativo conocer la lista de los beneficiados en este tiempo por el «rey» Alfonso, entre los que encontramos nuevamente a varios personajes de ascendencia portuguesa. El marqués de Villena consiguió en estos años numerosos beneficios como diversos juros de heredad, diferentes autorizaciones, varios libramientos y rentas reales ${ }^{25}$. Su

22 1465.06.05. PalencIa, Crónica de Enrique IV, libro VII, cap. VIII.

23 Morales MuñIz, M . Dolores-Carmen: Alfonso de Ávila, rey de Castilla, (Ávila) 1988, sobre la corte alfonsina cfr., pp. 337-359.

24 Álvaro de Estúñiga, conde de Plasencia estaba casado con Leonor Pimentel.

25 Sirvan como ejemplo los siguientes documentos: 1465.10.18. Arévalo. El infante Alfonso titulándose rey manda que se pague a Juan Pacheco las rentas de un juro situado en Huete, Murcia y Cartagena. A.H.N. Sección Nobleza, Frías, caja 661, doc. 27; 1466.01.03. Confirmación de 949.884 maravedies de juro de heredad destinados a la tenencia y paga de la villa de Xiquena 
mujer María Portocarrero fue beneficiada con las tercias de Moguer y juros de heredad ${ }^{26}$. También su hijo Alfonso Téllez se benefició con rentas ${ }^{27}$. A Pedro Girón, hermano de Juan Pacheco, se le autorizó en 1466 a repartir como quisiera los bienes de los seguidores de Enrique IV en Córdoba ${ }^{28}$. Alfonso Téllez Girón, conde de Urueña, recibió la confirmación de las tercias de Arévalo como las había tenido su padre el maestre de Calatrava, ya fallecido, y según se lo había otorgado Enrique IV ${ }^{29}$, así como diversas rentas. Alfonso Carrillo de Acuña, arzobispo de Toledo fue beneficiado con 160.000 maravedíes vitalicios por juro de heredad ${ }^{30}$, y con otros privilegios ${ }^{31}$. Su hijo Troilos Carrillo fue beneficiado con varias rentas ${ }^{32}$. Rodrigo Pimentel, conde de Benavente consiguió la villa de Portillo con su señorío por juro de heredad ${ }^{33}$, además de diversos derechos y ren-

situados en cualquier renta real. A.G.S. Mercedes y Privilegios, leg. 90, f. 13; 1466.02.26. Libranza de 150.000 maravedíes de juro de heredad situados en el obispado de Cuenca y Cartagena. Ibídem; 1466.04.15. Libramiento de un juro de heredad de 30.000 maravedíes en las rentas de la ciudad de Córdoba y su obispado. Ibídem; 1468.01.27. Alfonso titulándose rey ordena a los recaudadores del arcediano de Toledo que libren 600.000 maravedíes a Juan Pacheco para el pago de la gente que tiene a su servicio. A.H.N. Sección Nobleza. Frías, caja 7, doc. 7; 1468.04.03. Arévalo. El «rey» Alfonso ordena a los arrendadores de Segovia que den a Juan Pacheco las rentas de un juro de la reina Juana, por ocupar ésta la villa de Magaña que pertenecía al marqués. Ibídem, caja 661, doc. 30; 1468.04.28. Arévalo. El "rey" Altonso dispone que se den a Juan Pacheco las rentas de Carmona en atención a los gastos que tenía en la defensa de la villa y fortalezas. Ibídem, caja 7, doc. 9; 1468.05.14. El "rey" Alfonso manda a sus contadores que paguen a Juan Pacheco los gastos que había hecho para liberarle a él y a su hermana Isabel de la opresión en que los tenía la reína Juana. Ibídem, caja 7, doc. 10; 1468.05.16. Alfonso manda a los contadores mayores que paguen a Juan Pacheco los maravedíes de juro y de por vida y las raciones y quitaciones del año 1468 que están asentadas en los libros. Ibidem, caja 7 , doc. 11.

26 1467.10.23. A.G.S. Mercedes y Privilegios, leg. 11, f. 114

27 1466. El «rey" Alfonso hizo merced a Alfonso Téllez de las rentas del almojarifazgo de las ciudades, villas y lugares del obispado de Cartagena. A.H.N. Sección Nobleza. Frías, caja 7, doc. 6.

${ }^{28}$ También en 1466 recibió la orden de pago y finiquito de las rentas que se le debían A.H.N. Sección Nobleza. Osuna, 105, n. ${ }^{\circ} 9$.

29 1466.09.20. A.G.S. Mercedes y Privilegios, leg. 12, f. 43.

30 En 1465.09 .08 además de 60.000 maravedíes de juro de heredad en cualquier renta real 1468.03.08. A.G.S. Mercedes y Privilegios, leg. 47, f. 21.

${ }^{31}$ 1466.02.20. Permiso para tener acémilas en su casa $o$ en otro lugar cercano a la frontera de Aragón y Navarra. Ibídem, leg. 6, f. 92; 1466.08.13 la alcaidía de Ávila con 120.000 maravedíes de salario. A.G.S. Escribania Mayor de Rentas, Tenencia de Fortalezas, leg. 1; 1467.05.15. Con 650 doblas de oro de la banda castellana por juro de heredad confiscadas a los herederos de Álvaro de Luna. A.G.S. Mercedes y Privilegios, leg. 6, f. 92.

32 1465.09.10.97.000 maravedies por juro de heredad situados en lugar no especificado. Ibídem, leg. 47, f. 52; 1467.08.28, 10.000 maravedies por juro de heredad. Ibidem, leg. 6, p. 81. 1468.01.20. Con 200.000 maravedíes por juro de heredad y con 200.000 maravedies en los diezmos de las alcabalas y puerto de la villa de Molina y su tierra. Ibídem, leg. 47, f. 52; 1468.01.25 con tercias de Molina por juro de heredad. Ibídem, leg. 61, f. 8 .

33 1465.09.23. A.H.N. Sección Nobleza. Osuna, 518, n. ${ }^{\circ} 1$. 
tas $^{34}$. Leonor Pimentel, condesa de Plasencia recibió la confirmación de un juro sobre las alcabalas y almojarifazgo de Sevilla ${ }^{35}$ y otras rentas ${ }^{36}$. Su marido Álvaro de Estúñiga, conde de Plasencia recibió en 1465 la alcaidía de Burgos. También sus hijos recibieron diversos beneficios: Diego 60.000 maravedies vitalicios ${ }^{37}$ y Pedro 40.000 y 60.000 juros de heredad en cualquier lugar, además de 1000 quintales de aceite en la venta del diezmo del aceite de Sevilla ${ }^{38}$. Pedro de Acuña fue beneficiado con el título de conde Buendía por juro de heredad ${ }^{39}$. Luis Portocarrero, señor de Palma del Río, recibió 90.000 maravedíes de juro de heredad ${ }^{40}$ además de otros benefi$\operatorname{cios}^{41}$. Vázquez de Acuña recibió en 1465 la alcaidía de Huete y diferentes rentas $^{42}$.

Volviendo a los sucesos generales, tras los acontecimientos de Ávila, Enrique IV ordenó que dejasen el partido del infante Alfonso y le obedecieran como legítimo rey ${ }^{43}$, ante la falta de respuesta mandó que se hiciese la guerra al marqués de Villena y a los suyos. Pero ya era demasiado tarde, una vez proclamado "rey" muchos nobles siguieron al príncipe Alfonso, perdiendo así el rey castellano numerosos apoyos. Comenzaron tres años de enfrentamiento, de división y violencia en el reino que, sin llegar a ser una guerra como tal ya que apenas hubo batallas, reduciéndose el enfrentamiento a los cercos y sitios de ciudades y villas, si produjeron la división y anarquía en Castilla ${ }^{44}$. Junto a la lucha se iniciaron las negociaciones entre los dos bandos. A esto se sumaba la difícil situación jurídica motivada por le deposición de un rey y el alzamiento de uno nuevo. Se

34 1465.10.21. Señorio de la mitad de la villa y fortaleza de Puebla de Sanabria. Ibidem, $489, n .^{\circ}$; 1465.11.12. Rentas de las alcabalas, pedidos y monedas de la villa de Benavente, tierra y lugares del obispado de Astorga. A.G.S. Mercedes y Privilegios, leg. $94, \mathrm{f} .24 ; 1465.12 .22$. Con 100.000 maravedíes de juro de heredad en cualquier renta real y en 1468.01 .15 , con 500.000 maravedies. Ibídem.

$35 \quad$ 1465.08.20. A.H.N. Sección Nobleza. Osuna, 217, n. $^{\circ} 7$.

36 1466. A.G.S. Mercedes y Privilegios, leg. 11, 1.125.

37 1466.03.30. A.G.S. Mercedes y Privilegios, leg. 57, f. 88.

$38 \quad 1465.08 .23$ y 1467.06.07. A.G.S. Mercedes y Privilegios, leg. 57, 1. 106.1467 .06 .08 .

A.H.N. Sección Nobleza. Osuna, leg. $312, n .{ }^{\circ} 2$.

39 1465.06.09 R.A.H. Colección Salazar, M-92, ff. 266r-v

40 1468.03.26. R.A.H. Colección Salazar, M-117, ff. 239-240.

41 Como el 5\% de los pinos conducidos por el río Guadalquivir. 1468.03.27. Ibídem, ff. 56-57.

42 Como por ejemplo las siguientes: 1466.03.06. 6000 maravedíes por juro de heredad, y 6.000 maravedies de quitación vitalicios en cualquier renta no especificada. A.G.S. Mercedes y Privilegios, leg. 105, f. 103.

43 1465.07.15. A.H.N. Sección Nobleza. Frías, caja 16, doc. 16.

44 «Los reinos de Castilla y León, divididos en tales bandos, quedaron expuestos a calamidades más terribles que las hasta allí sufridas; pero que no lo hubieran sido tanto, si el ánimo de los Grandes, inclinado a la tiranía, no hubiese tendido en ambos a la destrucción de la República (...)", Palencia, Crónica de Enrique IV, libro VII, cap. X. 
acudió a Roma y el Papa durante esta contienda apoyó a Enrique IV como el legítimo rey de Castilla.

Nuevamente las maniobras del marqués de Villena modificaron el curso de los acontecimientos; no le interesaba ver derrocado a Enrique IV ya que la ambigua situación creada, sin duda, le beneficiaba ${ }^{45}$. Trató de alargar los preparativos del enfrentamiento armado para forzar nuevos negociaciones y llegar a una tregua ${ }^{46}$ en la que adoptó, con aprobación de ambos bandos, el papel de mediador. Según nos narra la crónica Juan Pacheco continuó en los siguientes meses engañando a los dos reyes con su ambigua postura; por un lado mantenía entrevistas con Enrique IV, y por otro dirigía el partido que apoyaba al "rey" Alfonso ${ }^{47}$.

Pedro Girón fue un personaje destacado del reinado de Enrique IV que normalmente actuaba a la sombra de su hermano el marqués de Villena, figura clave del momento. Con todo, como maestre de Calatrava participó de los grandes acontecimientos del reino, pero al igual que lo advertimos en su hermano, Juan Pacheco, la búsqueda de grandeza y enriquecimiento estuvo siempre presente en sus actuaciones ${ }^{48}$. En concreto en Andalucía trató de conseguir un gran patrimonio familiar que legar a sus descendientes, fundando un señorio y consiguiendo que el maestrazgo de Calatrava fuera heredado por su hijo Rodrigo Téllez Girón. Andalucía fue, junto con Castilla, uno de los escenarios más importante en los acontecimientos del reino, el poder y autoridad del maestre de Calatrava en este territorio fue decisivo en los convulsos momentos del reinado de Enrique IV, de hecho fue en Andalucía donde primero se proclamó «rey» al infante Alfonso ${ }^{49}$. Pedro Girón que fue nombrado capitán general de la frontera y poseía un señorío centrado en Osuna y Morón, extendió por tierras andaluzas una gran actividad en favor del nuevo "rey", consiguiendo captar a los principales personajes andaluces para el bando alfonsino. Durante los años de dominio del «rey» Alfonso una de las características destacadas fue la institución del virreinato. La delegación del poder real

45 Ibídem, libro VIII, cap. I-II.

$46 \quad$ 1465.10.05.

47 Palencia, Crónica de Enrique IV, libro VIII, cap. IV

48 Como dice el cronista siguiendo $«(.$.$) el antiguo pacto entre ambos establecido a fin de uti-$ lizar la apatía y envilecimiento de D. Enrique y los pocos años de D. Alonso para aumentar su fortuna y extender su poderío (...)». Ibidem, libro IX, cap. I.

49 El 27 de abril de 1465 en la plaza mayor del mercado de Úbeda, Pedro Girón hizo la proclamación pública de Alfonso como rey de Castilla y la población levantó pendones y aclamó al nuevo rey. LoRA SerRano, G.: “La casa de Estúñiga durante el reinado de Enrique IV: orto política de un linaje nobiliario", en Actas III Jornadas Hispano-Portuguesas de Historia Medieval, 1991, (Sevilla) p. 1203. 
pleno provocó en Andalucía la intervención del linaje Girón-Pacheco, cuyos intereses personales y políticos superaron las tierras andaluzas ${ }^{50}$. En estos difíciles momentos para el reino castellano, Pedro Girón utilizó las tierras andaluzas como plataforma para sus proyectos y ambiciones al igual que su hermano, Juan Pacheco, lo hacia en Castilla. El maestre de Calatrava deseaba ocupar toda Andalucía por lo que no tardó en enfrentarse al condestable Miguel Lucas de Iranzo, fiel a Enrique IV. El enfrentamiento tuvo lugar en tierras de Jaén ${ }^{51}$, donde se apoderó de Baeza. Las revueltas continuaron por otros escenarios andaluces. Pedro Girón, cabeza de la rebelión en Andalucía, se tituló virrey en nombre del "rey" Alfonso. Bajo el dominio del maestre de Calatrava prácticamente toda Andalucía apoyó la causa del príncipe Alfonso. Encontramos cierto paralelismo entre lo que estaba ocurriendo en Castilla, por influencia de Juan Pacheco, con lo que ocurría en Andalucía con Pedro Girón. Ninguno buscaba una guerra rápida, ya que sus intereses políticos pasaban por el enriquecimiento personal que hiciera que su presencia en la corte fuera imprescindible. Este camino se conseguia más fácilmente con un largo proceso de enfrentamientos y luchas de los nobles con el monarca, del que lograrían, sin duda, mayores beneficios.

Tal es el poder y la ambición de los hermanos Pacheco-Girón que en la primavera de 1466 llegaron a negociar el matrimonio de la hermana de Enrique IV, Isabel, con el maestre de Calatrava. Creyeron de este modo ver colmado su deseo de convertirse en los personajes más poderosos del reino, ya que con este enlace su linaje emparentaría con la familia real. En este proyecto contaron con el apoyo de Enrique IV, que creyó que así se acabaría con la división del reino y conseguiría el apoyo del maestre y de los territorios que dominaba. Curiosamente el disparatado proyecto fue presentado al monarca por Alonso de Fonseca y Ulloa, arzobispo de Sevilla, nieto de un exiliado portugués en Castilla. Nuevamente advertimos la presencia de un descendiente de lusitanos ejerciendo una notable influencia política en la corte de Enrique IV. Finalmente y para alivio de la futura Reina Católica, este enlace matrimonial no se celebró ya que Pedro Girón murió el dos de mayo de 1466 en Villarrubia de los Ojos, durante el camino que le llevaba a cumplir su ambicioso propósito ${ }^{52}$. Con todo, Pedro Girón consiguió dejar un importante legado a sus hijos y poner

\footnotetext{
50 Morales MuÑIZ, M. ${ }^{a}$ D-C. : “Andalucia ante la crisis de 1464: los años de Alfonso XII», en Revista Histórica, Literaria y Artística, (Sevilla), 1988, n. 216, p.4.

51 Palencia, Crónica de Enrique IV, libro VIII, cap. III.

52 Palencia, Crónica de Enrique IV, libro VIII, cap. III; F. UHAGÓN describe el final de Pedro Girón "jJusticias son del destino que castiga la humana ambición cuando parece lograda!", Órdenes Militares, Vda. de Tello, (Madrid) 1898.
} 
las primeras piedras de uno de las casas nobiliarias más grandes del reino. Durante veinte años ${ }^{53}$ había sido maestre de Calatrava, una de las Órdenes Militares más poderosas de Castilla, además consiguió fundar un mayorazgo para su hijo primogénito, y así poder mantener los bienes y perpetuar su linaje a través de los condes de Urueña, titulares del señorío de Osuna.

Pedro Girón en su testamento había nombrado como tutores de sus hijos, a su hermano Juan Pacheco, y en caso de fallecimiento de éste, a su tío, Alfonso Carrillo. Nuevamente nos encontramos con la presencia conjunta de estos personajes, miembros de la misma familia, cuyos intereses y ambiciones les han vinculando durante el reinado de Enrique IV. Su poder político era mayor a medida que su patrimonio y riqueza crecían. El marqués de Villena se ocupó en Andalucía de hacer cumplir el testamento de su hermano velando por el futuro de sus sobrinos. Actuó como virrey con amplísimos poderes, situación de la que saco importantes beneficios ${ }^{54}$. De hecho, consiguió que la presencia del linaje Pacheco-Girón en Andalucía continuase durante muchos años.

Volviendo a los acontecimientos generales del reino, las maniobras del marqués de Villena le llevaban a cambiar de bando cuando fuera oportuno para su beneficio personal ${ }^{55}$; apoyando al monarca o por el contrario organizando la liga nobiliaria frente al poder real ${ }^{56}$. A finales de 1466 el arzobispo de Toledo se encuentra ya cansado de las estratagemas de su sobrino el

53 De 1445 a 1466.

54 1468.04.23. Arévalo. El «rey» Alfonso dona a Juan Pacheco las deudas de alcabalas, tercias y pedidos de los lugares de la orden de Calatrava. A. H.N. Sección Nobleza. Frías, caja 665 , doc. 64 .

55 Por lo que no resulta extraño que la documentación muestre la doble actuación del marqués de Villena, encontrando documentos tanto de Alfonso, como ya hemos visto, como de Enrique IV otorgándole diferentes beneficios o distinciones. Del rey castellano pueden servir de ejemplo estos dos documentos: 1466.05.15. Cédula de Enrique IV autorizando a Juan Pacheco a que tomase criados para la casa real, de las ciudades de Úbeda, Baeza y Ciudad Real, y asentase con ellos los acostamientos que tendrían del rey, para que estas ciudades estuviesen más seguras a favor suyo. A.H.N. Sección Nobleza, Frias, caja 10, doc. $5 ; 1466.05 .15$. Enrique IV autoriza al marqués de Villena para que pueda tomar para la guarda y defensa de Carmona, los alcaides y un asistente que administre justicia, y los caballeros y escuderos de Carmona y su comarca, para que estén al servicio del rey, y que el marqués de Villena asiente las pagas y libramientos que deban corresponderles. Ibidem, caja 10, doc. 7.

56 Sabemos que resulta frecuente encontrar documentación que refleje la ambigua postura del marqués de Villena, un nuevo ejemplo podrian ser estos documentos de confederación y apoyo para el "rey" Alfonso y Juan Pacheco, y seguro de amistad de la reina Juana para el marqués de Villena: 1466.06.18. Confederación y homenaje entre Juan Pacheco y Alfonso Acuña, obispo de Jaén, ofreciéndose éste servir al "rey" Alfonso, al marqués de Villena y a su sobrino, hijos del maestre de Calatrava. Ibidem, caja 14, doc. 3; 1466.11.04. Coca. Seguro de amistad que hizo la reina Juana, mujer de Enrique IV al marqués de Villena. Ibídem, caja 14, doc. 4. 
marqués de Villena. Juan Pacheco no quería que el «rey» Alfonso resultase vencedor ni vencido, sino mantenerlo entre la fortuna y la desgracia y así poder manejar los acontecimientos del reino en su propio interés ${ }^{57}$. Tuvo lugar en ese tiempo la boda de su hija María con Rodrigo Alfonso Pimentel, el enlace supuso, entre otras cosas, una mayor colaboración del conde de Benavente en las ligas nobiliarias dirigidas por su suegro. Nuevamente el marqués de Villena tratará de no llegar a un enfrentamiento abierto que no le favorecía, sino de debilitar a los dos reyes ${ }^{58}$. Promovía las juntas y conferencias sabiendo que de la confusión de las mismas su poder salía fortalecido. En este tiempo comenzó su esfuerzo por hacerse con el maestrazgo de Santiago. Los nobles que apoyaban a Enrique IV no vieron con buenos ojos la preponderancia del marqués de Villena y advirtieron su estrategia al proclamar rey a un niño para poder manejarlo a su antojo. Incluso en su decidido ataque llegaron a aludir su humilde posición y su origen extranjero ${ }^{59}$.

En mayo de 1467 el rey de Aragón entraba nuevamente en la escena política castellana tratando de imponer una vez más la hegemonía aragonesa. Reorganizó la liga de nobles junto con el arzobispo Alfonso Carrillo y conociendo el peso político en Castilla del marqués de Villena buscó atraérselo con las negociaciones para el matrimonio de su hija con su heredero. De este modo Juan Pacheco retomaba la idea de emparentar con la familia real, en esta ocasión el proyecto matrimonial era entre Beatriz Pacheco, hija del marqués de Villena y el futuro rey Fernando el Católico, hijo de Juan II de Aragón.

Tras el fracaso de las negociaciones, los acontecimientos se precipitaron hacia el enfrentamiento entre los dos bandos, el cual tuvo lugar en agosto de 1467 en Olmedo ${ }^{60}$. En septiembre el marqués de Villena se adueñó de Segovia, ocasionándole a Enrique IV un gran golpe moral debido al valor que tenía para él dicha ciudad. La infanta Isabel quedó entonces en poder de Juan Pacheco. En Segovia el marqués de Villena se hizo investir maestre de Santiago ${ }^{61}$. Como afirma Suárez Fernández los

57 Palencia, Crónica de Enrique IV, libro Vill, cap. IX.

58 Alfonso de Palencia pone en boca de D. Fadrique esta ocurrencia sobre el modo de actuar de Juan Pacheco: «Este buen Marqués procura siempre mantener a los dos hermanos entre un círculo de todos los Grandes del reino, algunos de los cuales llaman rey a D. Enrique, como nosotros a D. Alfonso, y él puesto un pié, sobre el hombro de cada uno de los reyes, nos riega a todos en derredor con inmundo liquido", Ibídem, libro IX, cap. IV.

59 «(..) Sería preciso exterminar al corruptor tirano que, de nación extranjera, y desde posición humilde, habia llegado al ápice del poder y a un dominio sobre los naturales que ningún hombre independiente e integro podía sufrir ya más tiempo». Ibídem, libro IX, cap. VII.

60 Ibídem, libro IX, cap. VIII.

61 Ibídem, libro $X$, cap. II. 
tres últimos meses del año 1467 fueron los más tristes de la historia medieval castellana ${ }^{62}$.

Con todo, el tiempo jugará a favor del legítimo monarca que contaba, además de con la adhesión popular, con el apoyo de linajes como los Pimentel y los Estúñiga que volvieron a su obediencia. Las malintencionadas maniobras del marqués de Villena provocaban abandonos en sus filas debido, en gran parte, a su ambición de poder y encumbramiento social. Le abandonaran el obispo Fonseca y los condes de Benavente, Plasencia y Miranda ${ }^{63}$.

Cuando el cinco de julio de 1468 murió el infante Alfonso, el marqués de Villena se quedó sin su mejor arma política ${ }^{64}$. Trató entonces de volverse a reconciliar con el monarca mediante el reconocimiento de su hermana Isabel como heredera. Tuvieron lugar entonces los pactos de Guisando. Consiguió así Juan Pacheco tener en su poder a la legítima heredera al trono de Castilla, convirtiéndose nuevamente en árbitro de la situación política del reino. Aunque cambiasen las circunstancias siempre conseguía mantenerse en el poder, ser pieza clave en el entramado social y político castellano. A finales de 1468 advertimos como el equipo de gobierno está integrado por el marqués de Villena, el obispo Fonseca y los condes de Benavente y Plasencia. Incluso el monarca aragonés que apoyaba el matrimonio de su hijo Fernando con la princesa Isabel, conociendo el poder de Juan Pacheco trató, nuevamente, de buscar su amistad con el enlace de su hija Beatriz Pacheco con el hijo del infante aragonés, Enrique.

Hemos visto como en los difíciles años que tuvieron lugar entre la proclamación como "rey" del infante Alfonso y su muerte, apenas tres años después, Castilla vivió unos momentos de división y enfrentamiento. La institución monárquica en la persona de Enrique IV fue atacada, debilitada en sus funciones e insultada por un grupo de nobles que buscando, en su mayor parte, conseguir beneficios y poder, alzaron a un niño como "rey". Durante estos años fue la nobleza la que gobernó el reino utilizando la figura del rey, en un caso por juventud y en otro por debilidad. En ambos casos, tanto Alfonso como Enrique IV fueron títeres de un poder oligárquico que trataba de hacerse con el gobierno de Castilla. Durante estos años, el partido portugués formado por miembros de familias de ascendencia lusitana fueron protagonistas de los tristes sucesos.

\footnotetext{
62 "La monarquía, régimen político basado en la autoridad del rey, había dejado de existir», SuÁrez FERnÁndez, Nobleza y Monatquía, p. 221.

63 La crónica recoge la conjura de ciertos nobles contra el marqués de Villena, destacando la actuación de su yerno el conde de Benavente. PALENCIA, Crónica de Enrique IV, libro X, cap. IX.

64 Ibidem, libro $X$, cap. $X$.
} 